\title{
Textural and morphological studies on zinc-iron alloy electrodeposits
}

\author{
M KANAGASABAPATHY ${ }^{\mathrm{a}, *}$ and SOBHA JAYAKRISHNAN ${ }^{\mathrm{b}}$ \\ aDepartment of Chemistry, Rajapalayam Rajus' College, Affiliated to Madurai Kamaraj University, \\ Rajapalayam 626 117, India \\ ${ }^{b}$ EMFT Division, Central Electrochemical Research Institute, (Council of Scientific and Industrial Research), \\ Karaikudi 630 003, India \\ e-mail: rjpmks@yahoo.com
}

MS received 1 August 2010; revised 29 November 2010; accepted 14 January 2011

\begin{abstract}
Zinc-iron alloy electrodeposits have industrial significance, since they provide better corrosion resistance and with improved mechanical properties when compared to pure zinc coatings. This is due to the unique phase structure of the alloy formed. But this deposition belongs to anomalous deposition, where the electrochemically less noble zinc deposits more preferentially, than the more noble iron. So the industrial process control over the deposition becomes difficult. So, this study correlates the effect of various deposition parameters over the deposition kinetics and deposited alloy characteristics. Transition and partial current densities were computed. Effect of hydrogen overpotential and surface coverage due to the adsorbed intermediates over anomalous deposition were explored. Plausible deposition mechanism and mathematical model was proposed to predict the anomalous electrodeposition characteristics. Textural, morphological and phase structural characteristics of the alloy was investigated. By the substitution of iron in the hep lattice, c/a ratio was lowered and the lattice geometry was distorted. Intermetallic compounds of variable composition such as FeZn $\mathrm{n}_{14}$, $\mathrm{Fe}_{5} \mathrm{Zn}_{33}, \mathrm{Fe}_{3} \mathrm{Zn}_{13}$ and $\mathrm{FeZn} \mathrm{n}_{3}$ with ' $\eta$ ' and ' $\Gamma$ ' phase structures were noted. Electrodeposition parameters were optimized and smooth, adherent, strain-free deposits with required iron content and hardness were obtained.
\end{abstract}

Keywords. Zinc-iron alloy; anomalous electrodeposition; texture; morphology.

\section{Introduction}

Zinc coating is the most promising technique, to protect steel components from corrosion, since zinc is anodic to iron $\left(\mathrm{E}_{\mathrm{Zn}}^{0}=-0.76 \mathrm{~V}\right.$ and $\left.\mathrm{E}_{\mathrm{Fe}}^{0}=-0.44 \mathrm{~V}\right)$ and it provides sacrificial protection to steel. But under severe corrosive environments, zinc coating depletes rapidly from the steel surface. So to enhance the degree of protection and to meet the modern industrial standards, different zinc alloy coatings were studied. Among the various zinc alloy coatings, zinc alloyed with iron group metals $^{1-6}(\mathrm{Fe}, \mathrm{Ni}, \mathrm{Co})$ are having industrial significance since these alloy coatings are cathodic to pure zinc coatings but anodic to steel components. This study investigates specifically, the characteristics of zinc-iron alloy electrodeposition, since this zinc-iron alloy deposits provide three times higher corrosion resistance when compared to pure zinc deposits. In addition to that, due to the unique phase structure of the zinc-iron alloy, this coating has better mechanical properties ${ }^{7,8}$ such as

\footnotetext{
${ }^{*}$ For correspondence
}

hardness, adherence, weldability, etc. In order to get the desired degree of protection and mechanical properties, the coating should contain about 15-25 weight percent of iron. ${ }^{-11}$ But unlike other alloy deposition, this zinc-iron group alloy deposition belongs to anomalous co-deposition, ${ }^{12-14}$ where the electrochemically less noble zinc deposits more preferentially than the more noble iron group metals. So the industrial process control over the zinc-iron deposition becomes difficult. This study investigates the effect of various deposition parameters over the electrodeposition characteristics and the micro structural nature of the zinc-iron alloy formed.

\section{Experimental}

Electrodeposition of zinc-iron alloy was carried out from the sulphate bath. The optimized composition of the bath used for this study is as follows: $\left[\mathrm{ZnSO}_{4} .7 \mathrm{H}_{2} \mathrm{O}\right]-0.28 \mathrm{M} ;\left[\mathrm{FeSO}_{4}\left(\mathrm{NH}_{4}\right)_{2} \mathrm{SO}_{4} 6 \mathrm{H}_{2} \mathrm{O}\right]-$ $0.41 \mathrm{M}$ and $[\mathrm{KCl}]-1.07 \mathrm{M}$. In the bath, $\mathrm{KCl}$ was added to enhance the specific conductance ${ }^{15}$ and 
secondary current distribution. A small amount of disodium salt of EDTA $(0.08 \mathrm{M})$ was added to improve the bath stability. ${ }^{16}$ Deposition was done over mechanically polished and electrocleaned mild steel panels of size $5.0 \mathrm{~cm} \times 2.5 \mathrm{~cm} \times 0.05 \mathrm{~cm}$, under galvanostatic conditions by means of three electrode assembly, using a DC regulated power supply, (Aplab L3230 model, India make). The anode used was electrolytic grade zinc, with the same dimensions to that of cathode. Cathodic overpotential $\left(\eta_{c}\right)$ was measured at every 30 seconds at a given cathodic current density $\left(i_{c}\right)$ with reference to saturated calomel electrode through a Luggin probe assembly. ${ }^{17}$ Composition of this alloy was analysed by Energy Dispersive X-ray Analyser (Hitachi S-3000H model). Deposition was also carried out simultaneously, over mechanically polished and electrocleaned stainless steel panels of size $5.0 \mathrm{~cm} \times 2.5 \mathrm{~cm} \times 0.05 \mathrm{~cm}$, under the given conditions. After weighing, the alloy was dissolved in 20 volume percent nitric acid and this solution was made up to $100 \mathrm{ml}$. The alloy composition was then analysed by using Atomic absorption spectrophotometer (VARIAN Model SPECTRAA 220 model). Composition of the alloy was expressed in the weight percentage of iron $\left(\mathrm{p}_{\mathrm{Fe}}\right)$.

Based on the three electrode assembly, potentiostatic studies over glassy carbon electrode was carried out, by using Autolab PGSTAT 30 electrochemical analyzer (The Netherlands make). Glassy carbon electrode of area $0.25 \mathrm{~cm}^{2}$ (Tokai Carbon Company, Japan make) was used as the working electrode. Platinum foil of $2.5 \mathrm{~cm} \times 2.5 \mathrm{~cm}$ area was used as the counter electrode and saturated calomel electrode was used as the reference electrode. To eliminate the interference of oxygen, bath was purged by passing pure nitrogen for one hour.

Adhesion of the deposit over substrate was tested by the standard qualitative bend test to an angle of $180^{\circ}$ with a deposit thickness of $25 \times 10^{-6} \mathrm{~m}$. Microhardness of the coating was measured in Vicker's hardness number (VHN) by static indentation method, using Leco microhardness tester (Model M 400) at a given load for 15 seconds time duration. X-ray diffraction patterns were taken by using JEOL PANalytical, $X$ ' per PRO model. Samples were scanned between $20^{\circ}$ and $80^{\circ}, 2 \theta$ at a rate of $1^{\circ} \min ^{-1}$ using $\mathrm{Cu} \mathrm{K}_{\alpha}\left(\lambda=1.54 \mathrm{~A}^{\circ}\right)$ radiation. The hkl values were interpreted in accordance with ICDD. ${ }^{18}$ Lattice parameters such as ' $c$ ' and ' $a$ ' were computed based on d-spacing values for the given hkl planes. Scanning electron microscopic (SEM) images were obtained by using Hitachi S $-3000 \mathrm{H}$ model.

\section{Results and discussion}

\subsection{Electrochemical kinetics}

Effect of current density, temperature and stirring of the bath over the weight percentage of the iron in the alloy composition $\left(\mathrm{p}_{\mathrm{Fe}}\right)$ was studied and given in figure 1 . Iron content in the alloy increased, if the current density $\left(i_{c}\right)$ was increased (table 1). Though the weight percentage of iron in the bath was higher than zinc, the deposit has lower iron percentage than that of bath CR (Composition Reference) Line. At the same time if the bath temperature was increased or if the bath was stirred then the iron content in the alloy lowered.

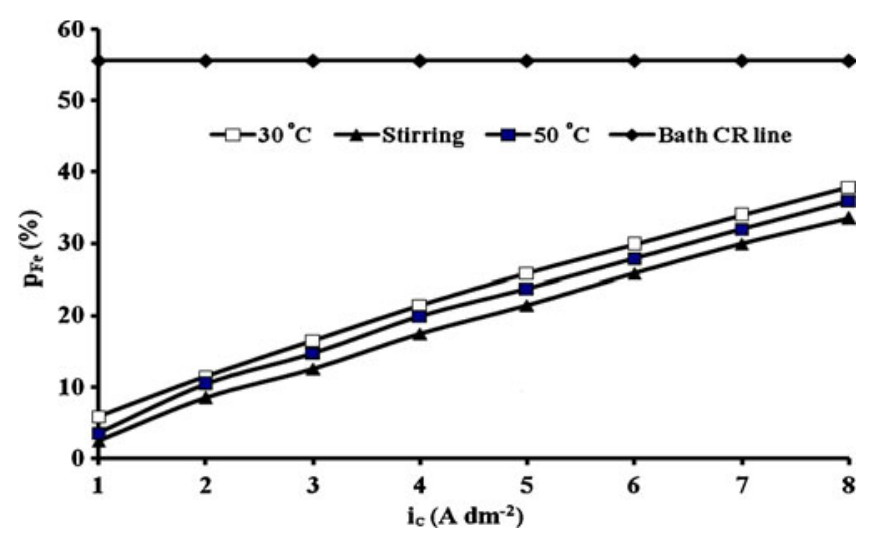

Figure 1. Effect of deposition parameters over alloy composition.

Table 1. EDAX data of alloy composition at different current densities and at $30^{\circ} \mathrm{C}$.

\begin{tabular}{lccc}
\hline \multirow{2}{*}{ Sl No. } & $\mathrm{i}_{\mathrm{c}}\left(\mathrm{A} \mathrm{dm}^{-2}\right)$ & \multicolumn{2}{c}{ Alloy composition (weight percent) } \\
\cline { 3 - 4 } & & Zinc & Iron \\
\hline 1. & 1 & 94.2 & 5.8 \\
2. & 2 & 88.6 & 11.4 \\
3. & 3 & 83.5 & 16.5 \\
4. & 4 & 78.6 & 21.4 \\
5. & 5 & 74.2 & 25.8 \\
6. & 6 & 70.2 & 29.8 \\
7. & 7 & 66.1 & 33.9 \\
8. & 8 & 62.2 & 37.8 \\
\hline
\end{tabular}




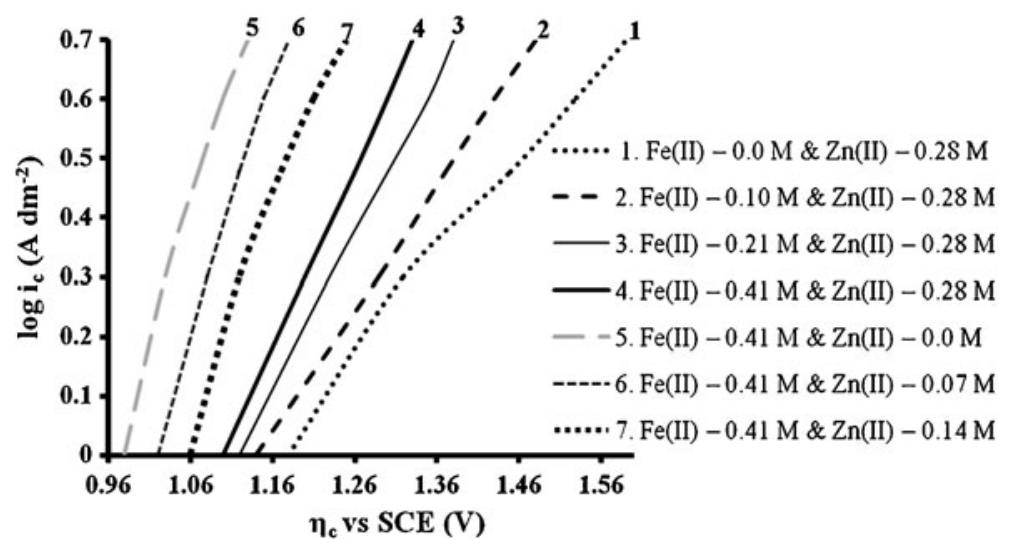

Figure 2. Tafel plot for the variation of $\mathrm{Fe}^{2+}$ and $\mathrm{Zn}^{2+}$ concentrations.

Tafel plot for the variation of $\mathrm{Fe}^{2+}$ and $\mathrm{Zn}^{2+}$ concentration under galvanostatic condition was given in figure 2. This shows that if the concentration of $\mathrm{Fe}^{2+}$ in the bath was increased, then the cathodic overpotential shifted less negatively. The current density obtained by extrapolation of polarization data values ${ }^{19}\left(i_{\mathrm{o}}\right)$ were noted from figure 2 . It decreased, if the $\mathrm{Fe}^{2+}$ concentration was increased. The value was about $1.99 \times 10^{-4}$ A dm ${ }^{-2}$ at $0.41 \mathrm{M}$ and about $1.58 \times 10^{-2} \mathrm{~A} \mathrm{dm}^{-2}$ in the absence of $\mathrm{Fe}^{2+}$. Similarly, potentiostatic studies were carried out (figure 3 ) and from this it was observed that in presence of $\mathrm{Fe}^{2+}$ the cathodic current was increased but the cathodic peak potential was shifted less negatively in forward scan. So it was confirmed that in presence of $\mathrm{Fe}^{2+}$, the overall cathodic potential was reduced, due to the lowering of deposition rate by

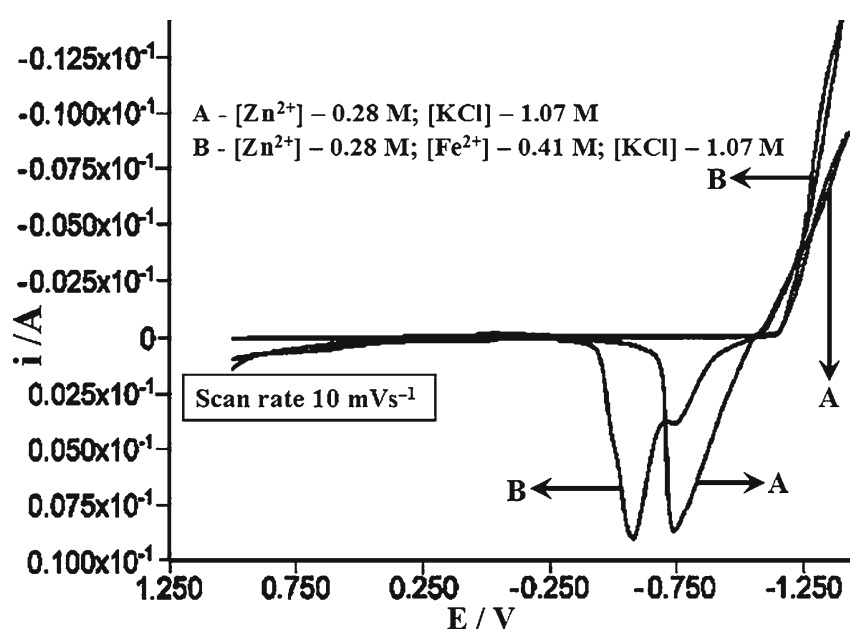

Figure 3. Potentiostatic studies. kinetic control processes. But the anodic peak potential was shifted less negatively and during the reverse scan two anodic peaks were noted. This shows that the alloy dissolution $^{20,21}$ takes place under two different potential values. Zinc-rich alloy undergoes anodic dissolution at more negative potential $(-0.725 \mathrm{~V})$ whereas ironrich alloy undergoes dissolution at less negative anodic potential $(-0.585 \mathrm{~V})$.

From these studies it can be revealed that the deposition of iron is hindered by charge-transfer control process at lower $i_{c}$ values, where as the deposition rate of zinc is lowered by mass-transport limitations at relatively higher $i_{c}$ values. Though the interface is enriched with $\mathrm{Fe}^{2+}$, at lower $i_{c}$ values, its deposition rate is impeded due to charge-transfer limitations. But it was shown by Gomez et al. ${ }^{22}$ at higher $\mathrm{i}_{\mathrm{c}}$ values the deposition rate of $\mathrm{Zn}^{2+}$ is very high in the initial stages of deposition when compared to $\mathrm{Fe}^{2+}$. And this leads to rapid depletion of $\mathrm{Zn}^{2+}$ at the electrode-electrolyte interface. But due to the mass transfer limitations of $\mathrm{Zn}^{2+}$ (from bulk to electrode interface), deposition rate of $\mathrm{Fe}^{2+}$ is enhanced. The mass transfer limitations of $\mathrm{Zn}^{2+}$ can be lowered by convection process such as through bath stirring or by increasing the bath temperature. By the forced convection, the diffusion layer is quickly enriched with $\mathrm{Zn}^{2+}$ and so the deposition rate of zinc can be increased.

\subsection{Mathematical correlation}

The value of weight percentage of iron content of the alloy, $\mathrm{p}_{\mathrm{Fe}}(\mathrm{x})$ at a given cathodic current density, $\mathrm{i}_{\mathrm{c}}(\mathrm{x})$ was predicted using Lagrange interpolation of irregular intervals. Values of apparent current densities, 
$\mathrm{i}_{\mathrm{c}}(1), \mathrm{i}_{\mathrm{c}}(2) \ldots \mathrm{i}_{\mathrm{c}}(\mathrm{n})$ and its corresponding weight percentage of iron content of the alloy $\mathrm{p}_{\mathrm{Fe}}(1)$,
$\mathrm{p}_{\mathrm{Fe}}(2) \ldots \mathrm{p}_{\mathrm{Fe}}(\mathrm{n})$ can be correlated by the following relation:

$$
\begin{aligned}
& \mathrm{p}_{\mathrm{Fe}}(x)=\frac{\left\{\left[\mathrm{i}_{\mathrm{c}}(x)-\mathrm{i}_{\mathrm{c}}(2)\right] \times\left[\mathrm{i}_{\mathrm{c}}(x)-\mathrm{i}_{\mathrm{c}}(3)\right] \times \ldots \times\left[\mathrm{i}_{\mathrm{c}}(x)-\mathrm{i}_{\mathrm{c}}(\mathrm{n}-1)\right] \times\left[\mathrm{i}_{\mathrm{c}}(x)-\mathrm{i}_{\mathrm{c}}(\mathrm{n})\right]\right\} \times \mathrm{p}_{\mathrm{Fe}}(1)}{\left\{\left[\mathrm{i}_{\mathrm{c}}(1)-\mathrm{i}_{\mathrm{c}}(2)\right] \times\left[\mathrm{i}_{\mathrm{c}}(1)-\mathrm{i}_{\mathrm{c}}(3)\right] \times \ldots \times\left[\mathrm{i}_{\mathrm{c}}(1)-\mathrm{i}_{\mathrm{c}}(\mathrm{n}-1)\right] \times\left[\mathrm{i}_{\mathrm{c}}(1)-\mathrm{i}_{\mathrm{c}}(\mathrm{n})\right]\right\}} \\
&+ \frac{\left\{\left[\mathrm{i}_{\mathrm{c}}(x)-\mathrm{i}_{\mathrm{c}}(1)\right] \times\left[\mathrm{i}_{\mathrm{c}}(x)-\mathrm{i}_{\mathrm{c}}(3)\right] \times \ldots \times\left[\mathrm{i}_{\mathrm{c}}(x)-\mathrm{i}_{\mathrm{c}}(\mathrm{n}-1)\right] \times\left[\mathrm{i}_{\mathrm{c}}(x)-\mathrm{i}_{\mathrm{c}}(\mathrm{n})\right]\right\} \times \mathrm{p}_{F e}(2)}{\left\{\left[\mathrm{i}_{\mathrm{c}}(2)-\mathrm{i}_{\mathrm{c}}(1)\right] \times\left[\mathrm{i}_{\mathrm{c}}(2)-\mathrm{i}_{\mathrm{c}}(3)\right] \times \ldots \times\left[\mathrm{i}_{\mathrm{c}}(2)-\mathrm{i}_{\mathrm{c}}(\mathrm{n}-1)\right] \times\left[\left(\mathrm{i}_{\mathrm{c}}(2)-\mathrm{i}_{\mathrm{c}}(\mathrm{n})\right]\right\}\right.} \\
&+\ldots+\frac{\left\{\left[\mathrm{i}_{\mathrm{c}}(x)-\mathrm{i}_{\mathrm{c}}(1)\right] \times\left[\mathrm{i}_{\mathrm{c}}(x)-\mathrm{i}_{\mathrm{c}}(2)\right] \times \ldots \times\left[\left(\mathrm{i}_{\mathrm{c}}(x)-\mathrm{i}_{\mathrm{c}}(\mathrm{n}-2)\right] \times\left[\left(\mathrm{i}_{\mathrm{c}}(x)-\mathrm{i}_{\mathrm{c}}(\mathrm{n})\right]\right\} \times \mathrm{p}_{\mathrm{Fe}}(\mathrm{n}-1)\right.\right.}{\left\{\left[\mathrm{i}_{\mathrm{c}}(\mathrm{n}-1)-\mathrm{i}_{\mathrm{c}}(1)\right] \times\left[\mathrm{i}_{\mathrm{c}}(\mathrm{n}-1)-\mathrm{i}_{\mathrm{c}}(2)\right] \times \ldots \times\left[\mathrm{i}_{\mathrm{c}}(\mathrm{n}-1)-\mathrm{i}_{\mathrm{c}}(\mathrm{n}-2)\right] \times\left[\mathrm{i}_{\mathrm{c}}(\mathrm{n}-1)-\mathrm{i}_{\mathrm{c}}(\mathrm{n})\right]\right\}} \\
&+\frac{\left\{\left[\mathrm{i}_{\mathrm{c}}(x)-\mathrm{i}_{\mathrm{c}}(1)\right] \times\left[\mathrm{i}_{\mathrm{c}}(x)-\mathrm{i}_{\mathrm{c}}(2)\right] \times\left[\mathrm{i}_{\mathrm{c}}(x)-\mathrm{i}_{\mathrm{c}}(3)\right] \times \ldots \times\left[\mathrm{i}_{\mathrm{c}}(x)-\mathrm{i}_{\mathrm{c}}(\mathrm{n}-1)\right]\right\} \times \mathrm{p}_{\mathrm{Fe}}(\mathrm{n})}{\left\{\left[\mathrm{i}_{\mathrm{c}}(\mathrm{n})-\mathrm{i}_{\mathrm{c}}(1)\right] \times\left[\mathrm{i}_{\mathrm{c}}(\mathrm{n})-\mathrm{i}_{\mathrm{c}}(2)\right] \times\left[\mathrm{i}_{\mathrm{c}}(\mathrm{n})-\mathrm{i}_{\mathrm{c}}(3)\right] \times \ldots \times\left[\mathrm{i}_{\mathrm{c}}(\mathrm{n})-\mathrm{i}_{\mathrm{c}}(\mathrm{n}-1)\right]\right\}} .
\end{aligned}
$$

Based on this the weight percentage of iron content in the alloy, $p_{\mathrm{Fe}}$ at a given $\mathrm{i}_{\mathrm{c}}$ value at $30^{\circ} \mathrm{C}$ can be correlated by the following II order polynomial equation: $\mathrm{p}_{\mathrm{Fe}}=-\mathrm{ai}_{\mathrm{c}}^{2}+\mathrm{bi}_{\mathrm{c}}$, where $\mathrm{a} \approx 0.15$ and $\mathrm{b} \approx 4 \mathrm{a}$. The experimentally determined alloy composition at a given $\mathrm{i}_{\mathrm{c}}$, was concurred with predicted values and less than $\pm 2.0 \%$ deviation was observed over the range of $i_{c}$ values studied. The transition current density, $\mathrm{i}_{\mathrm{t}}$ (at which anomalous deposition becomes normal co-deposition) at $30^{\circ} \mathrm{C}$ was determined under galvanostatic condition and it was $14.2 \mathrm{Adm}^{-2}$. The corresponding weight percent of iron in the alloy is 56.28. The deviation from the predicted value was found to be $-1.2231 \%$.

\subsection{Effect of hydrogen overpotential}

Partial current density values were determined and correlated to the surface coverage of metal intermediates formed, under the influence of hydrogen evolution reaction (HER). Based on the Volmer, Tafel and Heyrovsky models of HER and subsequent surface coverage of intermediates adsorbed, following mechanisms were proposed. $\mathrm{M}^{+}$and $\mathrm{M}^{2+}$ represents metal ions or mono hydroxides ${ }^{23-27}$ or di hydroxides and $\theta_{M(I)}$, and $\theta_{M H}$ are cathodic surface coverage of $\mathrm{M}^{+}$(metal ions or their corresponding hydroxides) and $\mathrm{MH}$ (metal hydrides) respectively through adsorption. $r_{1}, r_{2} \ldots r_{6}$ are rate of the relevant reactions.

$$
\begin{aligned}
& \mathrm{M}^{2+}+\mathrm{e}^{-} \stackrel{\mathrm{K}_{\mathrm{M(N)}}}{\longrightarrow} \mathrm{M}_{(\mathrm{ads})}^{+} \\
& \mathrm{M}_{(\mathrm{ads})}^{+}+\mathrm{e}^{-} \stackrel{\mathrm{K}_{\mathrm{M}}}{\longrightarrow} \mathrm{M} \\
& \mathrm{M}+\mathrm{H}_{2} \mathrm{O}+\mathrm{e}^{-} \stackrel{\mathrm{K}_{\mathrm{MH}}}{\longrightarrow} \mathrm{MH}_{(\mathrm{ads})}+\mathrm{OH}^{-} \\
& \mathrm{M}+\mathrm{H}_{3} \mathrm{O}+\mathrm{e}^{-} \stackrel{\mathrm{K}_{\mathrm{MH}}^{\prime}}{\longrightarrow} \mathrm{MH}_{(\mathrm{ads})}+\mathrm{H}_{2} \mathrm{O}
\end{aligned}
$$

$$
\begin{aligned}
& \mathrm{MH}_{(\mathrm{ads})}+\mathrm{H}_{2} \mathrm{O}+\mathrm{e}^{-} \stackrel{\mathrm{K}_{\mathrm{H}}}{\longrightarrow} \mathrm{M}+\mathrm{OH}^{-}+\mathrm{H}_{2} \\
& \mathrm{MH}_{(\mathrm{ads})}+\mathrm{H}_{3} \mathrm{O}+\mathrm{e}^{-} \stackrel{\mathrm{K}_{\mathrm{H}}^{\prime}}{\longrightarrow} \mathrm{M}+\mathrm{H}_{2} \mathrm{O}+\mathrm{H}_{2} \\
& \mathrm{r}_{1}=\mathrm{K}_{\mathrm{M}(1)}\left[\mathrm{M}^{2+}\right]\left(1-\theta_{\mathrm{M}(\mathrm{I})}\right) \\
& \mathrm{r}_{2}=\mathrm{K}_{\mathrm{M}} \theta_{\mathrm{M}(\mathrm{I})} \\
& \mathrm{r}_{3}=\mathrm{K}_{\mathrm{MH}}\left(1-\theta_{\mathrm{MH}}\right) \\
& \mathrm{r}_{4}=\mathrm{K}_{\mathrm{M}(1)}^{\prime}\left[\mathrm{H}_{3} \mathrm{O}^{+}\right]\left(1-\theta_{\mathrm{MH}}\right) \\
& \mathrm{r}_{5}=\mathrm{K}_{\mathrm{H}} \theta_{\mathrm{MH}} \\
& \mathrm{r}_{6}=\mathrm{K}_{\mathrm{H}}^{\prime}\left[\mathrm{H}_{3} \mathrm{O}^{+}\right] \theta_{\mathrm{MH}} .
\end{aligned}
$$

Based on this the effective partial current density values for iron $\left(\mathrm{i}_{\mathrm{Fe}}\right)$ as well as zinc $\left(\mathrm{i}_{\mathrm{Zn}}\right)$ deposition and for hydrogen evolution $\left(i_{\mathrm{H}}\right)$ were determined and given in figure 4. The value of $i_{\mathrm{Fe}}$ was always lower than $i_{\mathrm{H}}$ value, at all current densities studied. This shows that the overall decomposition rate of the iron intermediates is lower than the decomposition rate of zinc intermediates. The estimated ${ }^{28}$ value of hydrogen overpotential for iron is about $0.53 \mathrm{~V}$ and for zinc $0.75 \mathrm{~V}$ at a concentration of $\left[\mathrm{H}^{+}\right]=1 \mathrm{M}$ at $1 \mathrm{Adm}^{-2}$. So it can be noted that the HER competes with the iron deposition rate rather than with zinc deposition rate. From this it can be

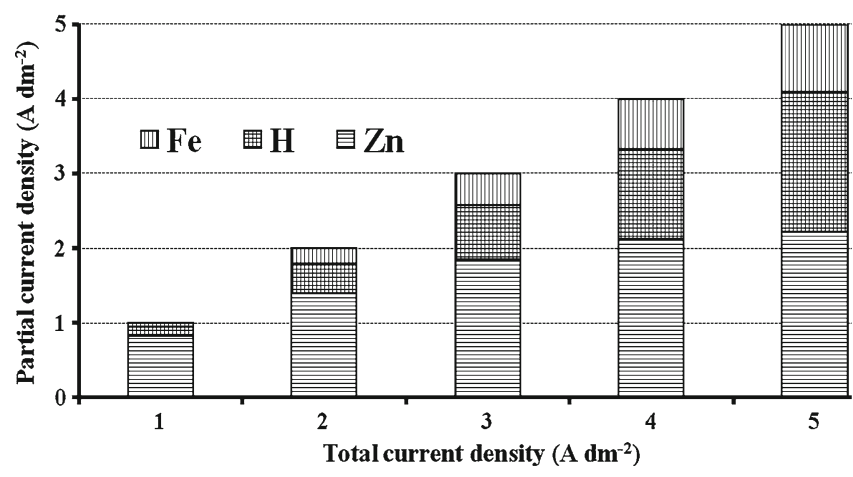

Figure 4. Effective partial current density values. 
elucidated that, though the interface was enriched with the $\mathrm{Fe}^{2+}$, reduction rate of iron was hindered by charge transfer limitations.

\section{$3.4 \quad$ XRD studies}

XRD patterns of the deposits at different current densities are given in figure 5. Pyramidal textural intensity was significant than the prismatic and basal textures. Generally, (101)hcp peak was present almost in all deposits with significant intensity. The peak noted at the $2 \theta$ value of $77^{\circ}$ was indexed to (004) plane. Textural intensity was relatively higher for the deposits obtained $2 \mathrm{~A} \mathrm{dm}^{-2}$. (200) $\alpha$ peak for iron was noted distinctly above $2 \mathrm{~A} \mathrm{dm}^{-2}$. Certain peaks representing specific crystallographic hkl plane gradually shifted either to higher or lower $2 \theta$ angles with the change in iron content in the deposit. Both 002 and 102 peak shifted to higher $2 \theta$, whereas 100 peak shifted to lower $2 \theta$, when the iron content in the deposit was increased. The 101 peak was not shifted significantly. These observed results are in accordance with previous reports. ${ }^{29,30}$ Interplanar spacing (d) for different hkl planes and the axial ratio (c/a) for deposits obtained at different $i_{c}$ values are given in figure 6 . Axial ratio value decreased from 1.86 (at $1 \mathrm{Adm}^{-2}$ ) to 1.66 (at $5 \mathrm{Adm}^{-2}$ ) or if the iron content was increased as observed by Kondo ${ }^{31,32}$ et al. This is due to lowering of the value of ' $c$ ' and the value of ' $a$ ' is almost constant for the hkl planes studied. This showed that the

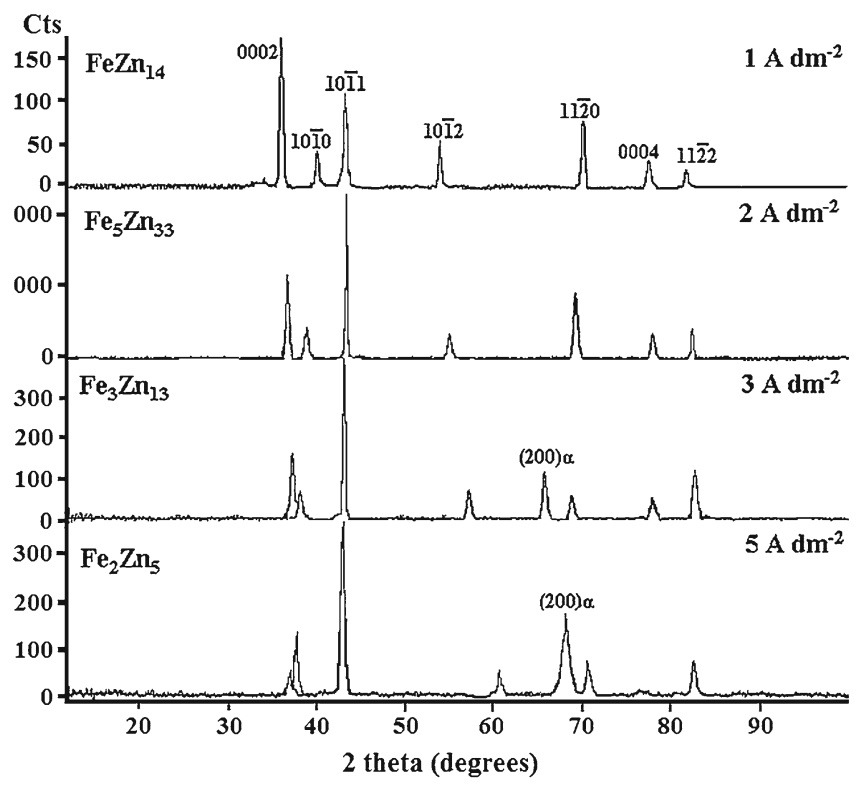

Figure 5. XRD patterns of the deposits for different $i_{c}$ values.

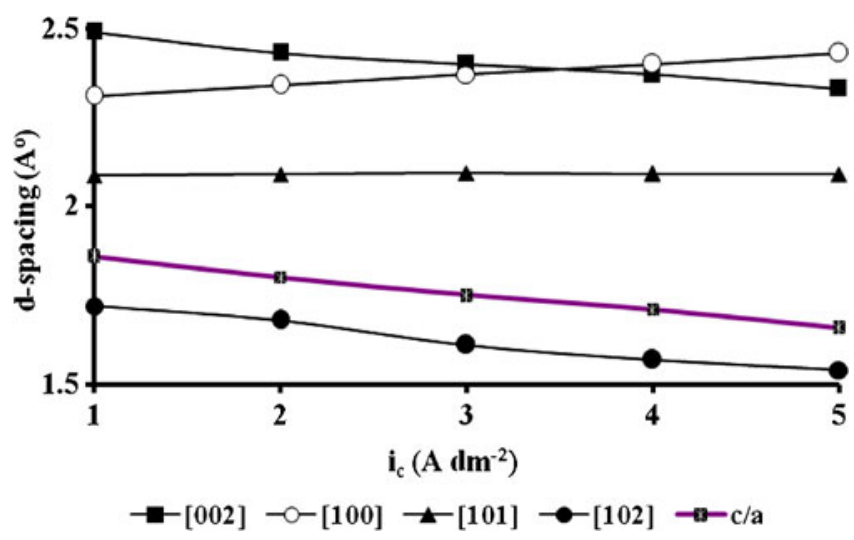

Figure 6. d-spacing and c/a values of deposits for different $\mathrm{i}_{\mathrm{c}}$ values.

hcp lattice geometry distorted, if the iron content was increased and the probability of substitution of iron along c-axis is more than a-axis, because the linear density along c-axis is lower. In other words the basal plane is tightly packed (six atoms) than the axial plane (three atoms).

Peak broadening due to internal lattice strain ${ }^{33}$ was not notified from the observed full width at half maxima (FWHM) values. This shows that adherent and strain free deposits were obtained under the conditions studied. The deposited alloy belongs to intermediate phase type, since the crystal structures of both metals are not same and the atomic volume ratio of iron to zinc is, $\sim 80 \%$. So, the substitution of iron atom in the hcp lattice, leads to change the lattice geometry and it lowers the axial ratio.

\subsection{Morphological characteristics}

From SEM images [figure 7], it was observed that the deposit morphology ${ }^{34}$ was influenced by the alloy composition. Three types of morphologies were observed. For zinc-rich alloy $(<10 \%$ iron content), distorted hexagonal $\left(1 \mathrm{~A} \mathrm{dm}^{-2}\right)$ morphology was noted. For an alloy with optimum (10-25\%) iron content, triangular pyramidal morphology $\left(2-4 \mathrm{~A} \mathrm{dm}^{-2}\right.$ ) was observed. Relatively smooth and compact deposit with fine-grained morphology (with an iron weight percentage of $\approx 17 \%$ ) was noted at $3 \mathrm{~A} \mathrm{dm}^{-2}$. Coarser deposits with stacked platelet coloumnar morphology were noted above $5 \mathrm{~A} \mathrm{dm}^{-2}$ (iron content $>25 \%$ ).

Reduction of crystallite size at $3 \mathrm{~A} \mathrm{dm}^{-2}$ indicates that the nucleation rate was higher than the grain growth rate. This indicates the overall deposition rate was predominantly controlled by charge-transfer processes rather than mass-transfer processes. But at higher 

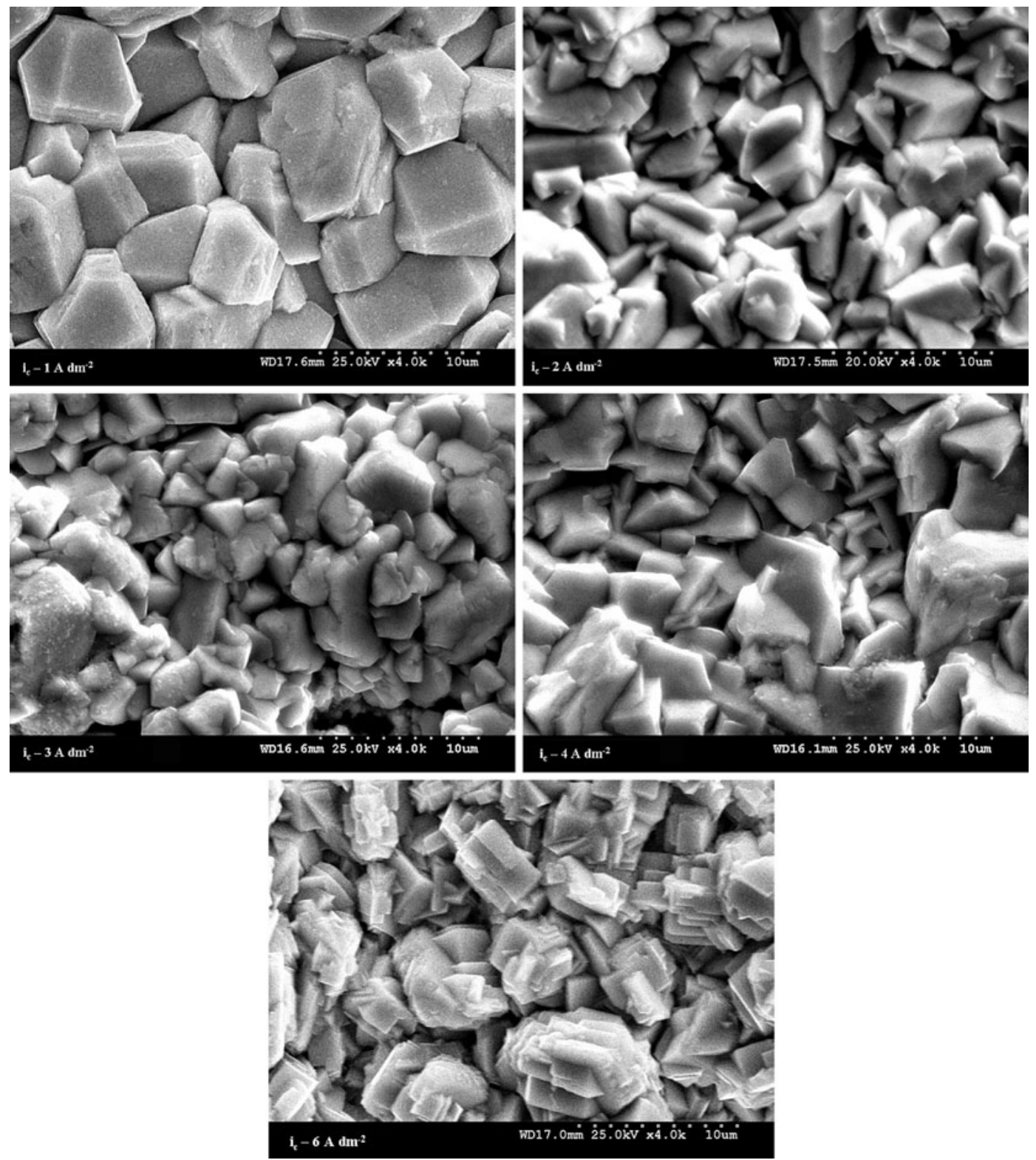

Figure 7. SEM images of deposits for different $i_{c}$ values.

current densities (above $5 \mathrm{~A} \mathrm{dm}^{-2}$ ) the overall deposition rate was controlled by mass transfer limitations particularly for zinc. So the grain growth rate was higher than the nucleation rate and this leads to the formation of coarser morphology enriched with iron.

\subsection{Microhardness}

Through the repeated standard qualitative bend test $\mathrm{t}^{35}$ it was observed that the deposits were highly adherent to the substrate without internal strain. Microhardness of the deposits obtained at $1 \mathrm{Adm}^{-2}$ was found to be 120.6 VHN and it increased to $156.7 \mathrm{VHN}$ at $5 \mathrm{Adm}^{-2}$. Microhardness of the deposit increased, if the iron content in the alloy was increased, since the hardness of the iron is relatively higher than the zinc. This microhardness value reflects the resistance of this coating towards plastic deformation and the abrasion resistance of this zinc-iron alloy coating is higher than pure zinc coating. 36,37

\subsection{Phase structure}

Very few studies with contrary views, ${ }^{31,32,38}$ over this alloy phase structure were reported. The phase structure of this electrodeposited alloy is different from thermally formed alloy phase structure. At lower iron content, $(<10 \% \mathrm{Fe})$ ' $\eta$ ' phase was dominant and if the 
iron content of the alloy was increased $(>10 \% \mathrm{Fe})$ then the ' $\Gamma$ ' phase augmented. Formation of phase structures can be correlated based on the composition of the alloy formed and deposition kinetics of metal ions. At lower current densities, the mass transport limitations for $\mathrm{Zn}^{2+}$ are not significant when compared to chargetransfer restrictions of $\mathrm{Fe}^{2+}$. So its grain growth rate is higher than that of nucleation rate. Hence the deposition of zinc ad-atoms are taking place gradually, leads to the formation of zinc-rich, distorted hcp ' $\eta$ ' phase. However, at higher current densities, the overall deposition process is limited by diffusion control processes. Due to this, the deposition rate of $\mathrm{Zn}^{2+}$ at the electrode interface is very fast when compared to its diffusion rate from the bulk of the solution. So, the electrode interface is enriched with $\mathrm{Fe}^{2+}$ due to the quick depletion of $\mathrm{Zn}^{2+}$ and this reduces the kinetic control limitations of $\mathrm{Fe}^{2+}$. So the ' $\Gamma$ ' phase is formed, by the adsorption of iron ad-atoms over the surface of previously formed zinc-rich ' $\eta$ ' phase.

Based on Hume-Rothery's rule this alloy belongs to intermetallic compounds of variable composition with metastable structures and exist as electron compounds of D- $8_{2}$ structure. ${ }^{31}$ It was observed that the low iron content intermetallic compounds such as $\mathrm{FeZn}_{14}$, have dominantly ' $\eta$ ' phase structure whereas the intermetallic compounds with moderate iron content, like $\mathrm{Fe}_{5} \mathrm{Zn}_{33}, \mathrm{Fe}_{3} \mathrm{Zn}_{13}$ and $\mathrm{FeZn}$ 3 are exist as with ' $\Gamma$ ' phase structure.

\section{Conclusion}

Anomalous electrodeposition behaviour of iron in the zinc-iron alloy formation was studied based on sulphate bath under galvanostatic and potentiostatic conditions. From the deposition kinetics and from the $i_{o}$ values, it was observed that, the overall deposition rate of iron was significantly reduced by charge-transfer process though the interface was enriched with $\mathrm{Fe}^{2+}$. The deposition rate of zinc was lowered only if the deposition was under diffusion controlled conditions. Under the mass transfer limitations of $\mathrm{Zn}^{2+}$, deposition rate of iron at the electrode interface was enhanced. From the hydrogen overpotential and transition as well as partial current density measurements, it was noted that the surface adsorbed intermediates appreciably favoured for HER rather than the reduction of $\mathrm{Fe}^{2+}$. The observed alloy content under the given cathodic current densities concurred with the proposed mathematical model. (101)hep plane was present almost in all deposits with significant intensity. If the iron content in the alloy was increased, c/a ratio decreased and also the hcp lattice geometry distorted, due to the substitution of iron along c-axis rather than a-axis. Distorted hexagonal morphology of the alloy was changed to triangular pyramidal and then to coloumnar structure, if the cathodic current density was increased. Microstructures of the alloy formed can be interpreted from the deposition rate. It was noted that the low iron content compounds such as $\mathrm{FeZn}_{14}$, have ' $\eta$ ' phase structure and the moderate iron content compounds, like $\mathrm{Fe}_{5} \mathrm{Zn}_{33}, \mathrm{Fe}_{3} \mathrm{Zn}_{13}, \mathrm{FeZn}_{3}$ have ' $\Gamma$ ' phase structure. The alloy composition and microstructure can be controlled through the proposed models. Smooth, adherent, strain-free deposits with required iron percentage and hardness were obtained as per industrial standards.

\section{References}

1. Lin Y P and Selman J R 1993 J. Electrochem. Soc. 140 303

2. Baldwin K R and Smith C J E 1996 Trans. IMF. 74, 202

3. Crotty D 1996 Met. Fin. 954

4. Zaki N 1999 Prod. Fin. 6353

5. Pushpavanam M 2000 Bull. Electrochem. 16559

6. Abou Krisha M M, Assaf F H and Toghan A A $2007 \mathrm{~J}$. Solid State Electrochem. 11244

7. Pech Canul M A, Ramanauskas R and Maldonado L 1997 Electrochim. Acta 42255

8. Hixon H G and Sherwood P M A 2001 J. Phys. Chem. 105 B 3957

9. Herb Geduld 1988 Zinc Plating (Ohio: ASM International, vol. 11, p. 237)

10. Sylla D, Savall C, Gadouleau M, Rebere C, Creus J and Refait Ph 2005 Surf. Coat. Technol. 2002137

11. Narasimhamurthy V and Sheshadri B S 1997 Met. Fin. 944

12. Dahms H and Croll I M 1965 J. Electrochem. Soc. 112 771

13. Higashi K, Fukushima H, Urakawa T, Takeshi Adaniya and Kazuo Matsudo 1981 J. Electrochem. Soc. 1282081

14. Tsuru T, Kobayashi S, Akiyama T, Fukushima H, Gogia S K and Kammel R 1997 J. Appl. Electrochem. 27209

15. An M, Zhang J, Yang Z and Wang H 1996 Mater. Prot. (China) 2912

16. Naik Y A, Venkatesha T V and Nayak P V 2002 Turk. J. Chem. 26725

17. Eliezer Giledi 1993 Electrode kinetics (New York: VCH Publishers Inc, vol. 8, p. 45)

18. International Centre for Diffraction Data, PDF-2, (JCPDS) 2000, Database 1- 49, Pennsylvania

19. Fratesi R and Roventi G 1989 Mater. Chem. Phys. 23 529

20. Pickering H W and Wagner C 1967 J. Electrochem. Soc. 114698 
21. Ravindran V and Muralidharan V S 2007 Trans. IMF. 85 153

22. Gomez E, Pelaez E and Valles E 1999 J. Electroanal. Chem. $\mathbf{4 6 9} 139$

23. Grande W C and Talbot J B 1993 J. Electrochem. Soc. 140675

24. Matlosz 1993 J. Electrochem. Soc. 1402272

25. Vaes J, Franser J and Celis J P 2000 J. Electrochem. Soc. 1473718

26. Diaz S L, Mattos O R, Barcia O E and Fabri Miranda F J 2002 Electrochim. Acta. 474091

27. Elumalai $\mathrm{P}$, Vasan $\mathrm{H} \mathrm{N}$, Munichandraiah $\mathrm{N}$ and Shivashankar S A 2002 J. Appl. Electrochem. 321005

28. Handbook of Electrochemistry, 2008, Society for Advancement of Electrochemical Science and Technology (SAEST), Karaikudi, Tamilnadu, India, $1.3,4$

29. Park H and Szpunar J A 1998 Corro. Sci. 40525
30. Karahan I H 2007 J. Mater. Sci. 4210160

31. Kondo K, Hinotani S and Ohmori Y 1988 J. Appl. Electrochem. 18154

32. Czerwinski F, Kondo K and Szpunar J A 1997 J. Electrochem. Soc. 144481

33. Drewien C A, Goldstein J I and Marder A R 1994 Metall. Mater. Trans. 25 A 249

34. Kondo K, Yokoyama M and Shinohara K 1995 J. Electrochem. Soc. 1422256

35. Dini J W 1992 Electrodeposition-The materials science of coatings and substrates (New York: Noyes Publications, vol. 3, p. 56)

36. Narasimhamurthy V and Sheshadri B S 1996 J. Appl. Electrochem. 2690

37. Panagopoulos C N, Agathocleous P E, Papachristos V D and Michaelides A 2000 Surf. Coat. Technol. 12362

38. Czerwinski F, Kondo K and Szpunar J A 1998 J. Mater. Sci. 332589 